\title{
Application of genus Cassia in the treatment of Constipation:
}

\section{A systematic review [version 1; peer review: 2 approved with}

\section{reservations]}

\section{Muhammad Shahzad Aslam}

Department of Chemistry, Xiamen University Malaysia, Sepang, Selangor, 43900, Malaysia

\author{
V1 First published: 05 Mar 2019, 8:256 \\ https://doi.org/10.12688/f1000research.17893.1 \\ Latest published: 08 Mar 2021, 8:256 \\ https://doi.org/10.12688/f1000research.17893.2
}

\section{Abstract}

Purpose: Role of genus cassia in the treatment of Constipation Methods: Methodological analysis, systematic review, and metaanalysis of identified studies using RevMan Result and Discussion: Cassia fistula was partially effected in treating constipation however there is a need for improvement in the protocol of studies to reduce biases. These results were only limited to one species so it cannot be generalized among all species of Cassia. Conclusion: Cassia fistula is partially effective in reducing the pain and consistency of stool during constipation among children.

Keywords

Cassia, Cassia fistula, Constipation, Pediatric gastroenterology

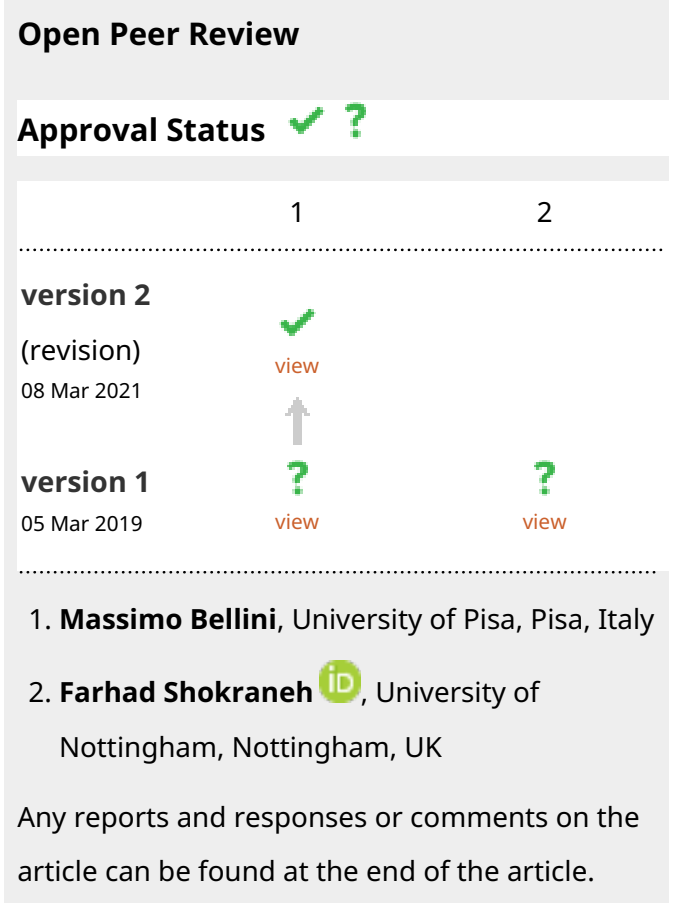

Corresponding author: Muhammad Shahzad Aslam (aslam.shahzad@xmu.edu.my)

Author roles: Aslam MS: Conceptualization, Data Curation, Formal Analysis, Funding Acquisition, Investigation, Methodology, Project Administration, Resources, Software, Supervision, Validation, Visualization, Writing - Original Draft Preparation, Writing - Review \& Editing

Competing interests: No competing interests were disclosed.

Grant information: This research was supported by Xiamen University Malaysia. The funders had no role in study design, data collection and analysis, decision to publish, or preparation of the manuscript.

Copyright: (c) 2019 Aslam MS. This is an open access article distributed under the terms of the Creative Commons Attribution License, which permits unrestricted use, distribution, and reproduction in any medium, provided the original work is properly cited.

How to cite this article: Aslam MS. Application of genus Cassia in the treatment of Constipation: A systematic review [version 1; peer review: 2 approved with reservations] F1000Research 2019, 8:256 https://doi.org/10.12688/f1000research.17893.1 First published: 05 Mar 2019, 8:256 https://doi.org/10.12688/f1000research.17893.1 


\section{Introduction}

Constipation is a clinical disorder attributed to ineffectual colonic impulsion and/or increased resistance to the proliferation of colonic matters ${ }^{1}$. Approximately $20 \%$ of the world population suffers from chronic constipation ${ }^{2}$. It is one of the most common pediatric problems ${ }^{3}$. It was found to be the second most stated disorder in the field of pediatric gastroenterology. Treatment costs for children with constipation will be around three times higher than children without constipation in the United States ${ }^{4}$. African American children, particularly girls, are greatly affected by constipation, which has been associated with poor hygiene conditions ${ }^{5}$.

Commonly, constipation is treated by Cisapride in children ${ }^{6}$, other treatments include polyethylene glycol 3350 and lactulose, however polyethylene glycol 3350 has been found to be more effective ${ }^{7}$. Supplemented and non-supplemented yogurt helps in reducing abdominal pain and to enhance defecation frequency $^{8}$. It has been observed that different species of Cassia act an effective as a laxative such as Cassia fistula, Cassia alata, and Cassia augustifolia ${ }^{9-11}$. The genus Cassia is well known in alternative medicine as hepatoprotective ${ }^{12}$, laxative, and in the treatment of ringworm infection ${ }^{13}$, skin diseases ${ }^{14}$ and leprosy ${ }^{15}$. It has many pharmacological properties including acting as a hypolipidemic agent ${ }^{16}$, anti-microbial ${ }^{17}$, anti-fungal ${ }^{18}$, and anti-cancer agent ${ }^{19}$. Genus Cassia contains a number of bioactive compounds such as anthraquinone ${ }^{20}$, $\operatorname{tannin}^{21}$, coumarins $^{22}$, triterpene, volatile oil ${ }^{23}$, phenolic glycoside $^{24}$, flavonoids ${ }^{25}$ from different parts of the plant. Different species of Cassia possess laxative properties due to various anthraquinone derivative such as aloe-emodin, rhein, chrysophanol and chrysoobtusin. In this review, we systematically assessed the laxative potential of different species of Cassia.

\section{Methods}

Literature search strategy

A systematic literature search was conducted in accordance with the Preferred Reporting Items for Systematic Reviews and Meta-Analyses (PRISMA) guidelines. Using the keywords (Senna AND Laxatives AND Clinical trial) (Cassia AND Laxatives AND Clinical trial) (Cassia AND Clinical trial) (Senna AND Clinical trial) and publication range from 01 January 1960 till 31
December 2018 for identification of the records. Table 1 shows the search strategy for PubMed Central. During screening of the records only full-length open access articles were considered. Abstract only or closed access articles were excluded ${ }^{11}$. Only articles involving children aged between 2-15 were included. All review articles, in-vivo studies and those $>10$ years from the search data were excluded. A preliminary search of the PubMed, CNKI, Scopus, Web of Science, Google Scholar and PsycINFO databases and digital archive such as PubMed Central, yielded 2207 papers published in English from the last ten years. Duplicate and irrelevant articles were removed $(n=2203)$. One article was further removed during screening due to closed access $(n=3)$. One publication was removed because the article did not meet the eligibility criteria $(n=2)$. A PRISMA Flow Diagram is given in Figure 1.

\section{Literature screening}

Identification of articles were performed at level 1 using the search strategy as mentioned in Table 1. Duplicate articles, irrelevant articles such as polyherbal formulation, review articles, or any article other than Cassia or Senna were removed at level 2. Only four ${ }^{4}$ articles were identified as being relevant. One record was excluded due to not being a full text article. Abstracts were being reviewed for the following inclusion and exclusion criteria at level 4 and one article was removed for not meeting the eligibility criteria i.e. Randomized, clinical trial on Constipation, full-length open access articles, Pediatric Functional Constipation (age range: $2-15$ years).

\section{Eligibility criteria}

Types of studies. The author has selected studies of randomized open label, prospective, controlled, parallel-group clinical trial for meta-analysis. Baseline characteristics of randomized trials of studies included on pediatric functional constipation are presented in Table 4. Characteristics of the studies included are mentioned in Table 5.

Types of participants. The author included studies involving patients (aged 2-15 years) with Functional constipation. The diagnosis of Functional constipation was according to according to the Rome III criteria ${ }^{26}$. Inclusion and exclusion criteria were based on Study design, participants, intervention, outcome (SPIO) criteria and indicated in Table 2.

Table 1. Search strategy.

\begin{tabular}{|c|c|}
\hline \multicolumn{2}{|c|}{ PubMed Central } \\
\hline $\begin{array}{l}\text { ("cassia"[MeSH Terms] OR "cassia"[All Fields]) } \\
\text { AND ("clinical trial”[All Fields] OR "clinical trials as } \\
\text { topic"[MeSH Terms] OR "clinical trial"[All Fields]) AND } \\
\text { ("1960/01/01"[PubDate]: "2018/12/31"[PubDate]) }\end{array}$ & $\begin{array}{l}\text { (("cassia"[MeSH Terms] OR "cassia"[All Fields]) AND } \\
\text { ("laxatives"[All Fields] OR "laxatives"[MeSH Terms] OR } \\
\text { "laxatives"[All Fields])) AND ("clinical trial"[All Fields] OR "clinical } \\
\text { trials as topic"[MeSH Terms] OR "clinical trial"[All Fields]) AND } \\
\text { ("1960/01/01"[PubDate] : "2018/12/31"[PubDate]) }\end{array}$ \\
\hline $\begin{array}{l}\text { ("Senna"[MeSH Terms] OR "Senna"[All Fields]) } \\
\text { AND ("clinical trial"[All Fields] OR "clinical trials as } \\
\text { topic"[MeSH Terms] OR "clinical trial"[All Fields]) AND } \\
\text { ("1960/01/01"[PubDate]: "2018/12/31"[PubDate]) }\end{array}$ & $\begin{array}{l}\text { (("senna plant"[MeSH Terms] OR ("senna"[All Fields] AND } \\
\text { "plant”[All Fields]) OR "senna plant"[All Fields] OR "senna"[All } \\
\text { Fields]) AND ("laxatives"[All Fields] OR "laxatives"[MeSH Terms] } \\
\text { OR "laxatives"[All Fields])) AND ("clinical trial”[All Fields] OR } \\
\text { "clinical trials as topic"[MeSH Terms] OR "clinical trial"[All Fields]) } \\
\text { AND ("1960/01/01"[PubDate] : "2018/12/31"[PubDate]) }\end{array}$ \\
\hline
\end{tabular}



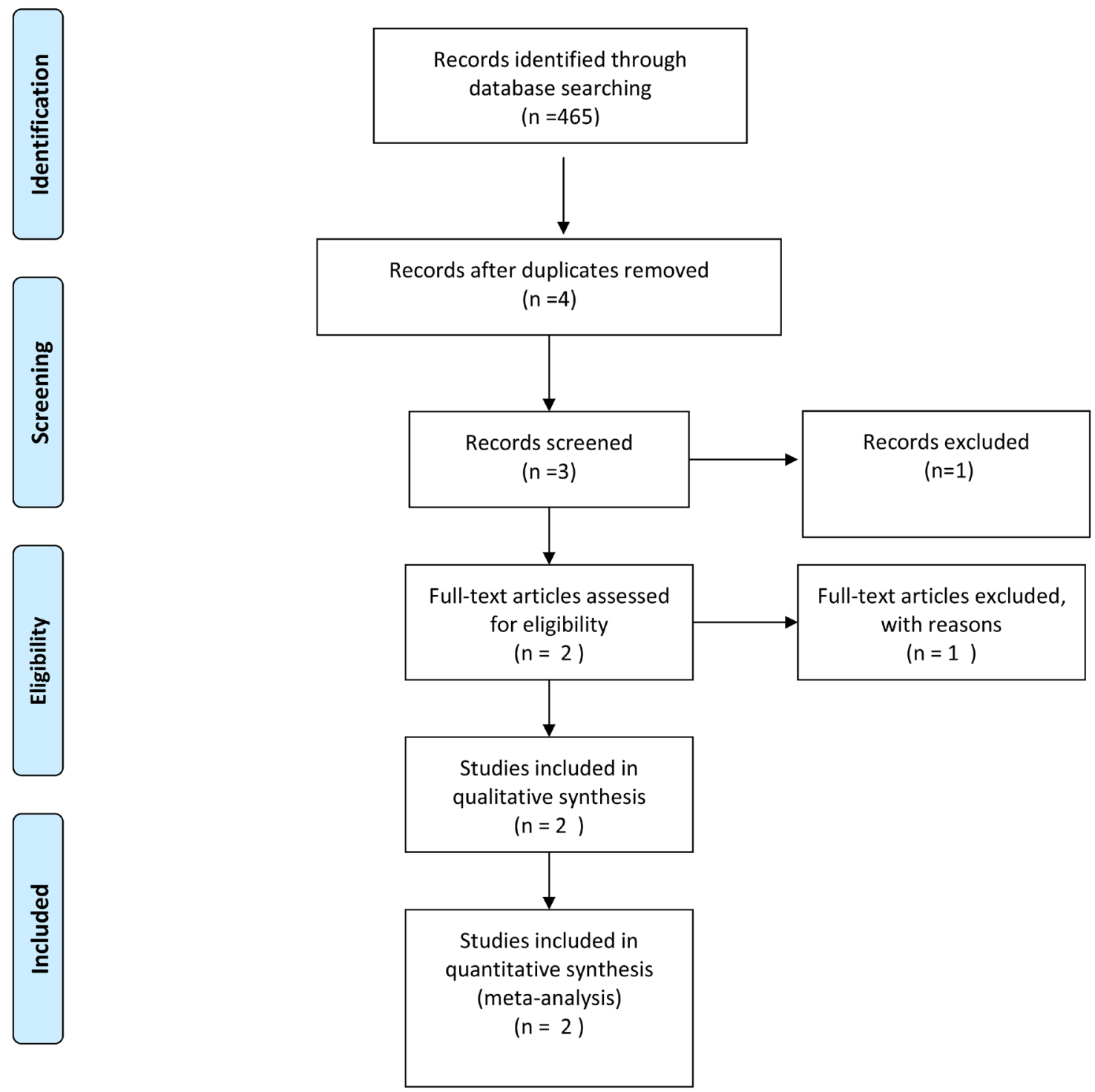

Figure 1. PRISMA flow diagram.

Types of interventions. Included studies were focused on the role Cassia in the treatment of Functional constipation. Unfortunately, there were only two studies identified.

Types of outcomes. Eligible studies included consisted of the following outcomes: improvement in the episodes of fecal incontinence per week, improvement in the episodes of retentive posturing per week, improvement in the average of severity of pain of defecation (by VAS), improvement in defecation frequency per week, patient's drug compliance and improvement in the average of consistency of stool defecated (by VAS).

Methodological quality assessment (MQ)

Methodological quality assessment was made on the basis of following criteria. 1) Aims and Hypothesis clearly defined, adequate sample representation, patient care quality, ethical approval protocol, outcomes assessment, validity and reliability of outcome measure,attempt to blind researcher, follow-up, appropriate statistical analysis and missing data reported. Ten item defined evaluation of methodological quality (MQ) is presented in Figure 2. Risk of Bias were assessed using Cochrane collaboration's tool on the basis of the following criteria such as selection bias, performance bias, attrition bias, reporting bias and miscellaneous. Cochrane Collaboration's tool for assessing the risk of bias was used and the results are presented in Table $6^{27}$.

\section{Data extraction}

The following data were extracted according to study characteristics (e.g., first author, year of publication, search dates, and number of included studies), patient characteristics (functional constipated children, aged between 2-15), sample size, study type (e.g., Randomized open label, prospective, controlled, 
parallel-group clinical trial study), randomization methods (e.g., "systematic randomization and simple randomization") and outcome measures/variables (e.g., improvement in defecation frequency per week, improvement in the episodes of fecal incontinence per week, improvement in the episodes of retentive posturing per week, improvement in the average of severity of pain ofdefecation (by VAS), improvement in the average of consistency of stool defecated (by VAS) and patient's drug compliance). Data extraction was performed by Muhammad Shazad Aslam. Transcripts were analysed, coded and data was extracted using the demo version ofqualitative data analysis software Atlas.ti 8.0 . Table 3 represent all the data that was extracted. All the meta-data are availableas Dataset 1.

\section{Statistical analysis}

Meta-analysis was conducted using the Review Manager (RevMan) 5.3 software ${ }^{28}$. The summary measures were reported as odds ratios (ORs) or as a standard mean difference (SMD) with $95 \%$ confidence intervals (CI). The presence of heterogeneity among trials was assessed using the Chi-square

Table 2. Study design; participants; intervention; outcome (SPIO) criteria.

\begin{tabular}{|l|l|l|}
\hline & Inclusion Criteria & Exclusion Criteria \\
\hline Study design & $\begin{array}{l}\text { Randomized, clinical trial on Constipation, full-length } \\
\text { open access articles, Pediatric Functional Constipation }\end{array}$ & $\begin{array}{l}\text { All review articles, irrelevant articles, Exclude } \\
\text { abstract only articles, clinical trial on adults. }\end{array}$ \\
\hline Participants & $\begin{array}{l}\text { Children (age range: 2-15 years) } \\
\text { Intervention }\end{array}$ & $\begin{array}{l}\text { Cassia fistula was delivered to Pediatric with Functional } \\
\text { Constipation }\end{array}$ \\
\hline Outcomes & $\begin{array}{l}\text { Role of the Cassia fistula emulsion in Pediatric Functional } \\
\text { Constipation }\end{array}$ & \\
\hline
\end{tabular}

Mozaffarpur, Esmaeilidooki, 2016

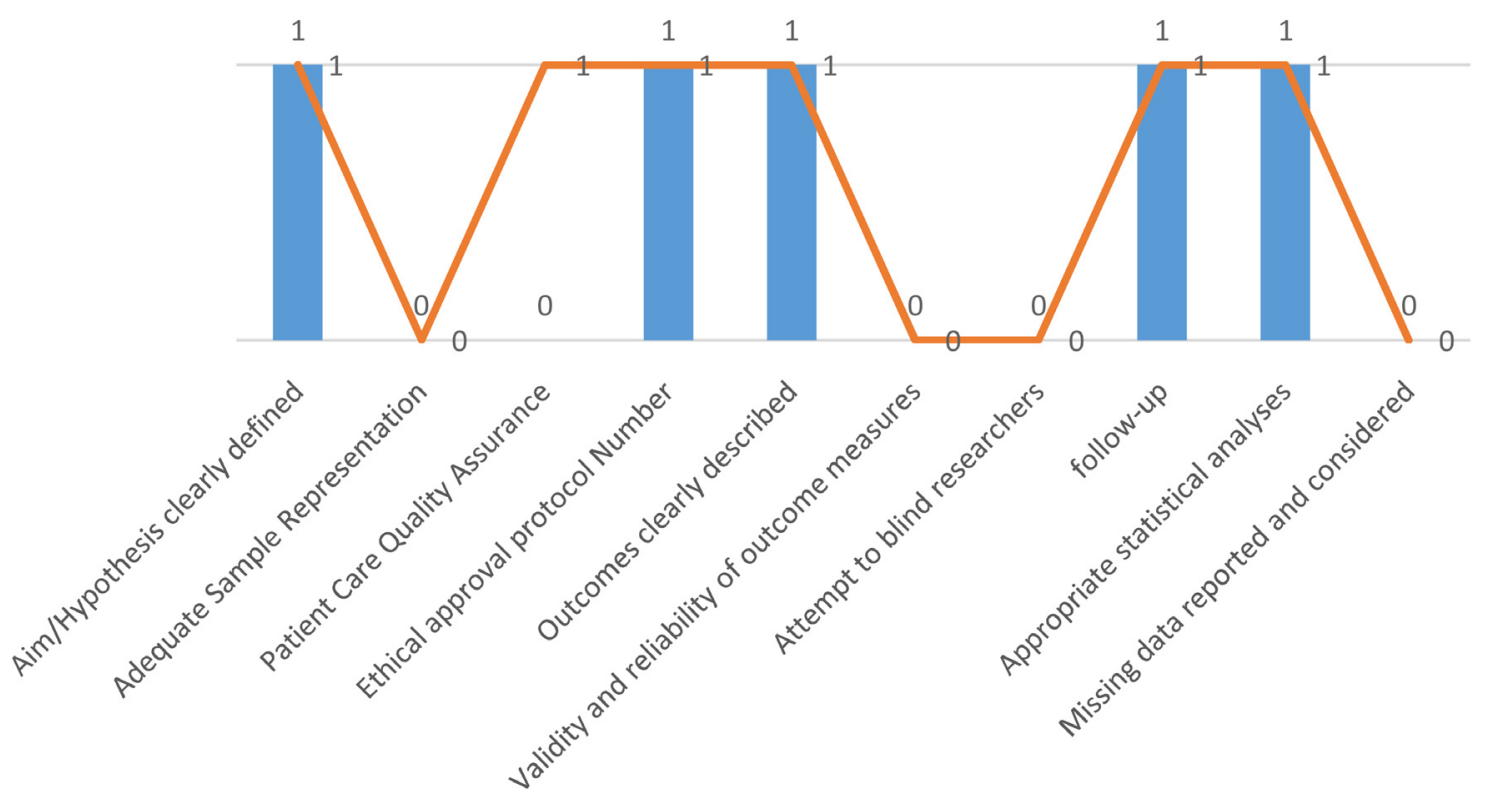

Figure 2. Methodological quality assessment of the 2 studies included in the meta-analysis (0=No/not reported, $1=$ Yes). 
Table 3. Data extraction.

\begin{tabular}{|c|c|c|}
\hline Characteristics & Seyyed Ali Mozaffarpur & Mohammad Reza Esmaeilidooki \\
\hline Publication Year & 2012 & 2016 \\
\hline Type of Study & Randomized, clinical trial & $\begin{array}{l}\text { This randomized open label, prospective, controlled, parallel- } \\
\text { group clinical trial study }\end{array}$ \\
\hline Age & Age between $4-13$ years & Aged between $2-15$ years \\
\hline Randomization & systematic randomization & Simple randomization \\
\hline Total Sample Size & 81 & 51 \\
\hline Variables & $\begin{array}{l}\text { Frequency of defecation, consistency } \\
\text { of stools, and severity of pain during } \\
\text { defecation, retentive posturing and } \\
\text { fecal incontinence per week }\end{array}$ & $\begin{array}{l}\text { Improvement in defecation frequency per week, improvement } \\
\text { in the episodes of fecal incontinence per week, improvement } \\
\text { in the episodes of retentive posturing per week, improvement } \\
\text { in the average of severity of pain of defecation (by VAS), } \\
\text { improvement in the average of consistency of stool defecated } \\
\text { (by VAS) and patient's drug compliance }\end{array}$ \\
\hline $\begin{array}{l}\text { Length of each contact with } \\
\text { the participant/caregivers }\end{array}$ & $\begin{array}{l}\text { Clinical efficacy and tolerance were } \\
\text { assessed using weekly sheets, } \\
\text { parents completed every night. They } \\
\text { were given three sheets (included } \\
\text { seven questions in seven columns) to } \\
\text { complete them daily for } 3 \text { weeks. }\end{array}$ & $\begin{array}{l}\text { During the study, we had regular phone calls with the parents } \\
\text { to check the probable complications, treatment (taking the } \\
\text { prescribed drugs) and data filling process. If there were any } \\
\text { serious questions or problems, we visited the child. At the end } \\
\text { of } 4 \text { weeks of treatment, the children were visited and the filled } \\
\text { out forms were taken and evaluated. }\end{array}$ \\
\hline Blinding of Experiment & $\begin{array}{l}\text { The investigators, the children and their } \\
\text { parents were aware of the study group } \\
\text { assignment. }\end{array}$ & $\begin{array}{l}\text { Fortunately, due to the developing socioeconomic conditions } \\
\text { of the people in these regions in recent years, we were able to } \\
\text { keep in touch with all the patients during the study period by } \\
\text { phone call. }\end{array}$ \\
\hline Diagnosis & $\begin{array}{l}\text { Rome III criteria of functional } \\
\text { constipation }\end{array}$ & Rome III criteria of functional constipation \\
\hline Diagnostic test & $\begin{array}{l}\text { Paraclinics like anorectal manometry, } \\
\text { thyroid function tests, anti-tTG, and } \\
\text { other laboratory tests }\end{array}$ & $\begin{array}{l}\text { thyroid function tests, anti-tTG, and etc. If it remained any } \\
\text { doubt, barium study and anorectal manometry would be } \\
\text { performed }\end{array}$ \\
\hline
\end{tabular}

test, and the extent of the inconsistency was measured by I2 statistics. Output file from RevMan is available as Underlying data $^{29}$.

\section{Results and discussion}

Both of the selected studies were not blinded during intervention and outcome assessment that will result in performance bias and detection bias respectively. These biases occur where the investigators know about the participant's treatment group. Performance bias can also refer to the fact that participants can change their responses or behaviour if they know which group they are allocated in. Blinding of outcome assessment may decrease the risk of the investigator or participant being aware of the treatment that a patient is receiving. If the participants and the caregivers are aware of the intervention and outcome that may affect the behavior of the participants, these behavioral changes may affect the performance of the treatment. Clinical trials on adults were also excluded, such as a randomized clinical trial of a phytotherapeutic compound containing Pimpinella anisum, Foeniculum vulgare, Sambucus nigra, and Cassia augustifolia for chronic constipation'. Results of both included studies were non-significant when comparing their baseline characteristics of pediatric functional constipation as presented in Table 5. During analysis of study characteristics, it was found that both of studies demonstrated Cassia fistula is helping to treat constipation among the children as shown in Table 3, but there is a risk of bias according to Cochrane Collaboration's tool (Table 6). Moreover, both studies found were from one country (Iran). During a methodological assessment, many flaws were identified such as inadequate patient care, attempt to blind the researcher and missing data (Figure 2). During meta-analysis, the comparison was made before and after treatment among different variables such as defaecation, fecal incontinence, retentive posturing, the severity of pain, and consistency of stool. All the variable (before and after treatment) were found to be symmetrical when plotted on a funnel plot as shown in Figure 4, Figure 6, Figure 8, Figure 10, Figure 12, and Figure 14 respectively. The overall effect for some variables is statistically insignificant $(\mathrm{P}=0.11$, $\mathrm{P}=0.49, \mathrm{P}=0.24$ ) such as fecal incontinence, retentive posturing, and acceptance, tolerance respectively. High heterogeneity was found in two variables i.e severity of pain (90\%) and consistency of stool (77\%). All the forest plot of defaecation, 
Table 4. Baseline characteristics of randomized trials of studies included in pediatric functional constipation.

\begin{tabular}{|c|c|c|c|c|c|}
\hline Variable in Treatment $(\mathrm{T})$ & $\begin{array}{l}\text { Mozaffarpur, } \\
2012 \text { (T) }\end{array}$ & $\begin{array}{l}\text { Esmaeilidooki, } \\
2016(T)\end{array}$ & $\begin{array}{l}\text { Mozaffarpur, } \\
2012 \text { (C) }\end{array}$ & $\begin{array}{l}\text { Esmaeilidooki, } \\
2016 \text { (C) }\end{array}$ & Variable in Control (C) \\
\hline Sample size in Treatment (N) & 41 & 52 & 40 & 57 & Sample size in Control (N) \\
\hline Age, months, Mean( \pm SD) & $69.4( \pm 24.3)$ & $64.6( \pm 25.2)$ & $65.9( \pm 19.1)$ & $55.2( \pm 31.2)$ & Age, months, Mean( $( \pm S D)$ \\
\hline Sex, Male, (n) (\%) & $29(70.7 \%)$ & 33 & $23(57.5 \%)$ & 30 & Sex, Male, (n) (\%) \\
\hline Weight, Kg Mean( $($ SD) & $21.7( \pm 7.2)$ & $20.5( \pm 7.2)$ & $20.7( \pm 7.8)$ & $18.5( \pm 8.9)$ & Weight, Kg(士SD) \\
\hline $\begin{array}{l}\text { Duration of constipation, } \\
\text { months, Mean( }(\mathrm{SD})\end{array}$ & $34.2( \pm 25.9)$ & $31.1( \pm 24.6)$ & $30.8( \pm 22.8)$ & $23.5( \pm 21.8)$ & $\begin{array}{l}\text { Duration of constipation, } \\
\text { months, Mean }( \pm S D)\end{array}$ \\
\hline Defecation $\leq 2$ per week, $\mathrm{n}(\%)$ & $32(78 \%)$ & 41 & $30(75 \%)$ & 52 & Defecation $\leq 2$ per week, $n(\%)$ \\
\hline Incontinence, $\mathrm{n}(\%)$ & $31(75.6 \%)$ & 34 & $27(67.5 \%)$ & 37 & Incontinence, $\mathrm{n}(\%)$ \\
\hline $\begin{array}{l}\text { History of previous treatment, } \\
\mathrm{n}(\%)\end{array}$ & $32(78 \%)$ & 43 & $28(70 \%)$ & 51 & $\begin{array}{l}\text { History of previous treatment, } \\
n(\%)\end{array}$ \\
\hline Retentive posturing, n (\%) & $32(78 \%)$ & 40 & $29(72.5 \%)$ & 37 & Retentive posturing, n (\%) \\
\hline
\end{tabular}

Table 5. Study characteristics.

\begin{tabular}{|c|c|c|c|c|c|}
\hline Author, year & Study Design & Hypothesis & Statistical analysis & Software & Outcomes \\
\hline Mozaffarpur, 2012 & $\begin{array}{l}\text { Randomized, } \\
\text { clinical trial }\end{array}$ & $\begin{array}{l}\text { The author } \\
\text { hypothesized } \\
\text { that Cassia fistula } \\
\text { emulsion (CFE) } \\
\text { would be as } \\
\text { effective or better } \\
\text { than Mineral oil } \\
\text { (MO) in treating FC. }\end{array}$ & $\begin{array}{l}\text { The statistical analyses included } \\
\text { the determination of means } \\
\text { and Standard deviation (SDs), } \\
\text { t test, } \chi 2 \text { test, ANOVA repeated } \\
\text { measures and Fisher's exact } \\
\text { test, with significance accepted } \\
\text { at the } 5 \% \text { level. }\end{array}$ & $\begin{array}{l}\text { SPSS (version } \\
17),\end{array}$ & $\begin{array}{l}\text { CFE was most effective } \\
\text { than } \mathrm{MO} \text { in the } 3 \text {-week } \\
\text { treatment of children } \\
\text { with FC. }\end{array}$ \\
\hline Esmaeilidooki, 2016 & $\begin{array}{l}\text { Randomized, } \\
\text { clinical trial }\end{array}$ & N/A & $\begin{array}{l}\text { The statistical analyses included } \\
\text { the determination of means } \\
\text { and SDs, t test, } \chi 2 \text { test, ANOVA } \\
\text { repeated measures and Fisher's } \\
\text { exact test, with significance } \\
\text { accepted at the } 5 \% \text { level. }\end{array}$ & $\begin{array}{l}\text { SPSS IBM20 } \\
\text { and STATA } 11.2\end{array}$ & $\begin{array}{l}\text { Significant improvement } \\
\text { when compared with } \\
\text { the control group } \\
\text { however unable to find } \\
\text { substantial evidence } \\
\text { of the role of identified } \\
\text { bioactive compounds } \\
\text { due to limitation as } \\
\text { it requires further } \\
\text { investigation }\end{array}$ \\
\hline
\end{tabular}

Table 6. Cochrane Collaboration's tool for assessing risk of bias.

\begin{tabular}{|l|l|l|l|l|l|l|}
\hline Study (author, year) & $\begin{array}{l}\text { Selection } \\
\text { bias }\end{array}$ & $\begin{array}{l}\text { Performance } \\
\text { bias }\end{array}$ & $\begin{array}{l}\text { Detection } \\
\text { bias }\end{array}$ & $\begin{array}{l}\text { Attrition } \\
\text { bias }\end{array}$ & $\begin{array}{l}\text { Reporting } \\
\text { bias }\end{array}$ & $\begin{array}{l}\text { Other } \\
\text { bias }\end{array}$ \\
\hline Mozaffarpur, 2012 & Unclear & Yes & Yes & No & No & Unclear \\
\hline Esmaeilidooki, 2016 & Unclear & Yes & Yes & No & No & Unclear \\
\hline
\end{tabular}

fecal incontinence, retentive posturing, severity of pain, consistency of stool and acceptance and tolerance are represented in Figure 3, Figure 5, Figure 7, Figure 9, Figure 11 and Figure 13 respectively.

\section{Conclusion}

After evaluation of results, it was found that Cassia fistula was not completely effective. It was partly effective in reducing the pain and consistency of stool during constipation. However, these results cannot be generalized among all population. A well designed, expert validated protocol is required in the future. There is a need to develop an instrument that will be free from bias. Moreover, the results cannot be generalized among all species of Cassia as the studies available are only for one species. There is a need to isolate identified bioactive compounds from different species of Cassia and evaluate the effect of different factors such as duration of constipation, defecation, incontinence or retentive posturing under clinical trial.

Page 6 of 16 


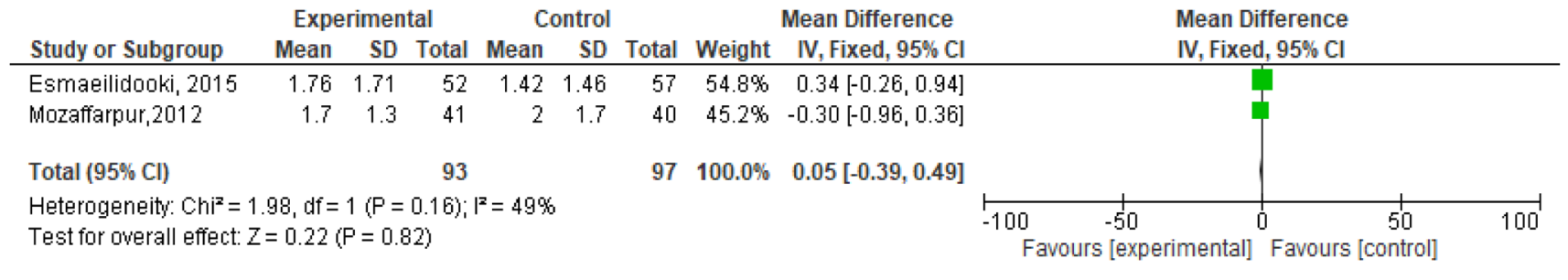

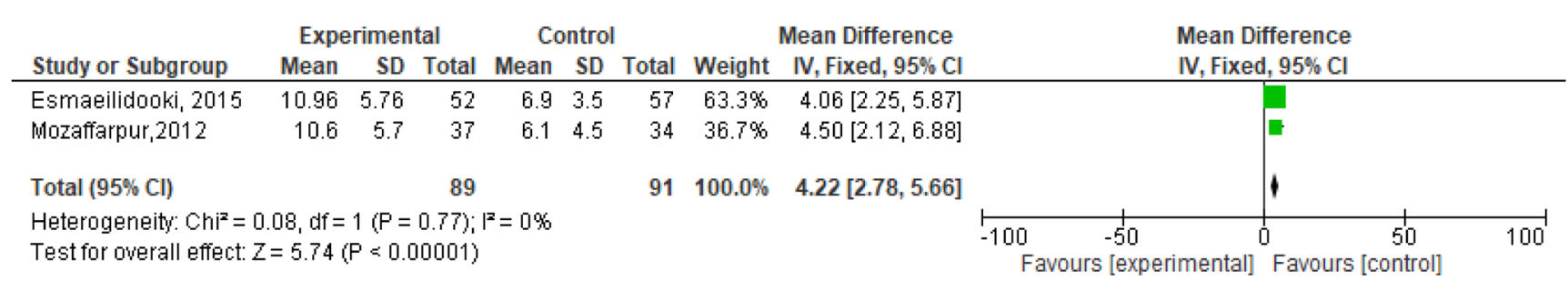

Figure 3. Forest plot in defaecation before and after treatment.

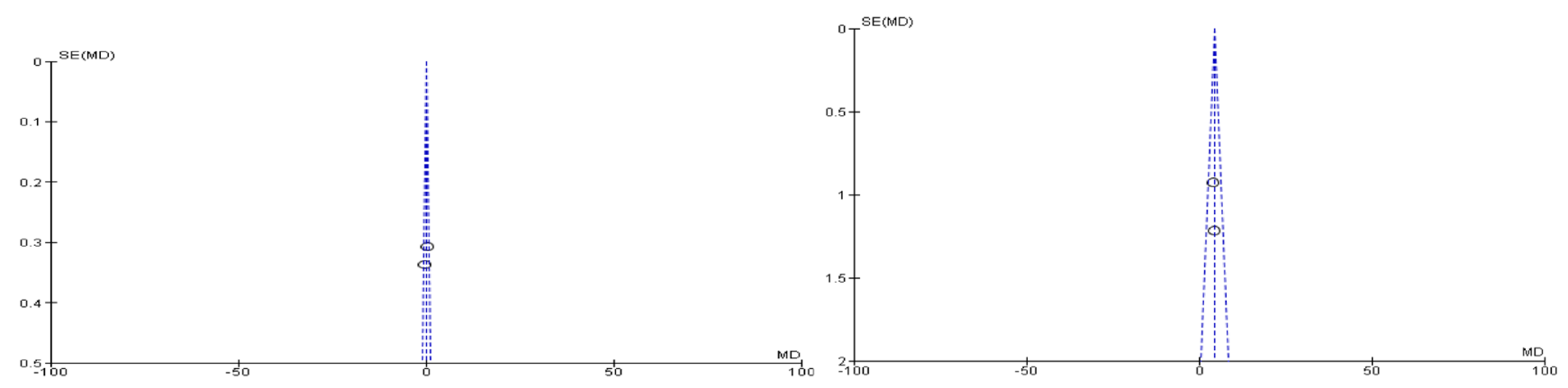

Figure 4. Funnel plot showing overall standardized mean difference in defaecation before and after treatment.

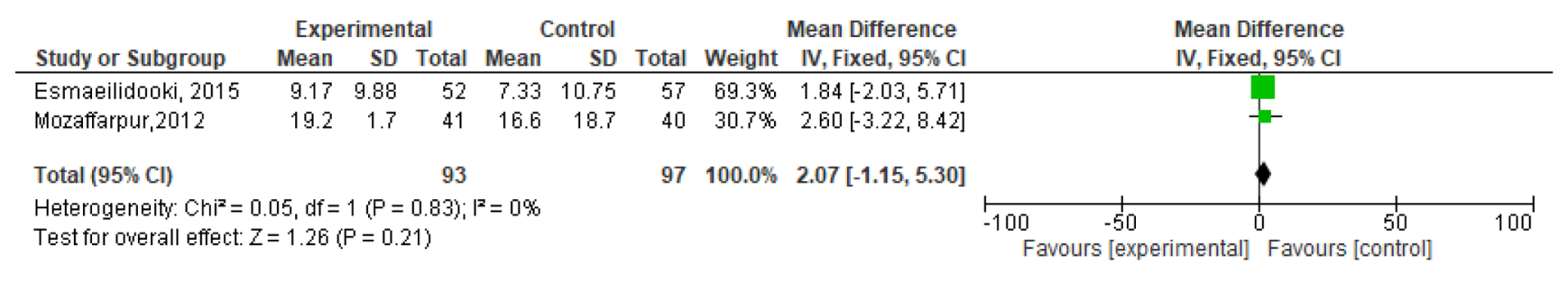

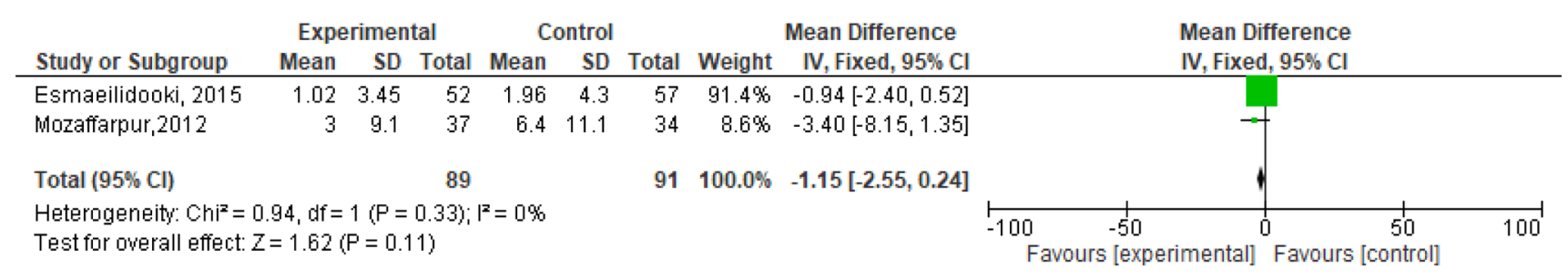

Figure 5. Forest plot in fecal incontinence before and after treatment. 

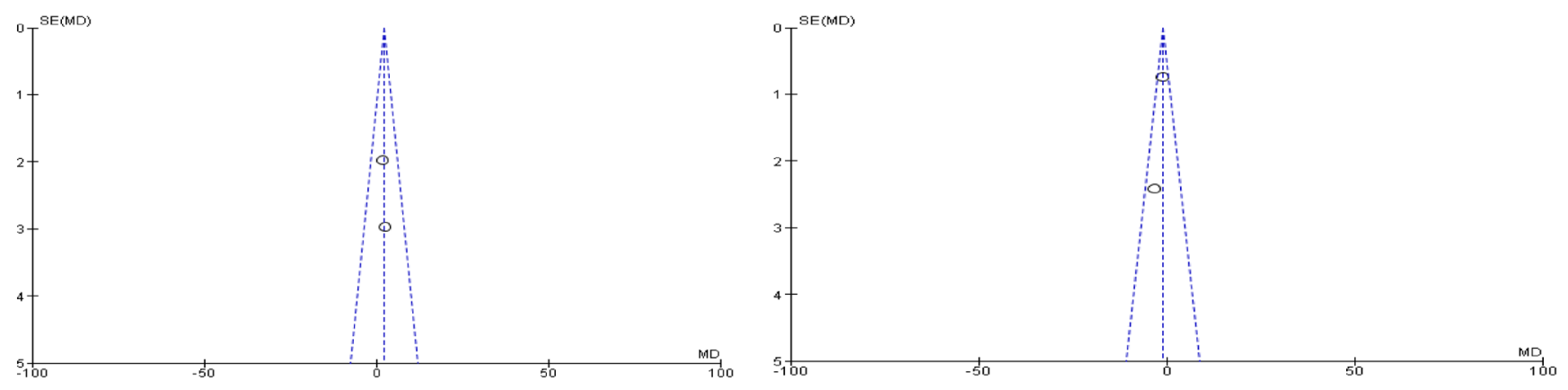

Figure 6. Funnel plot showing overall standardized mean difference in fecal incontinence before and after treatment.

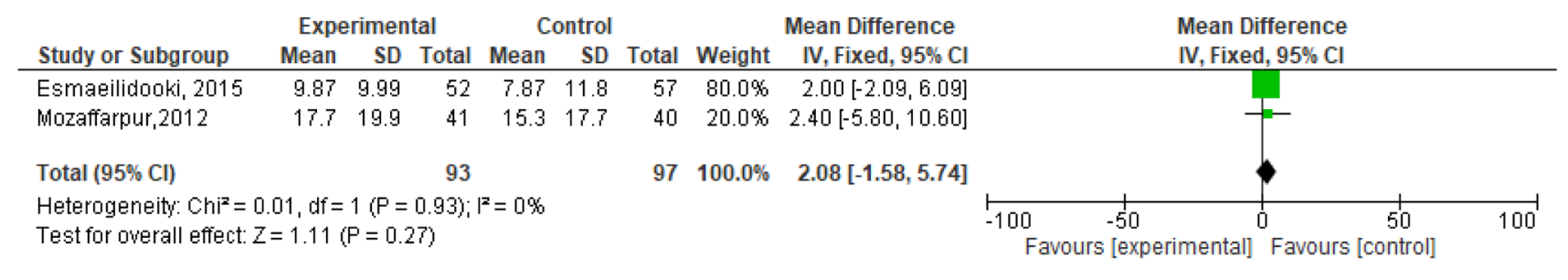

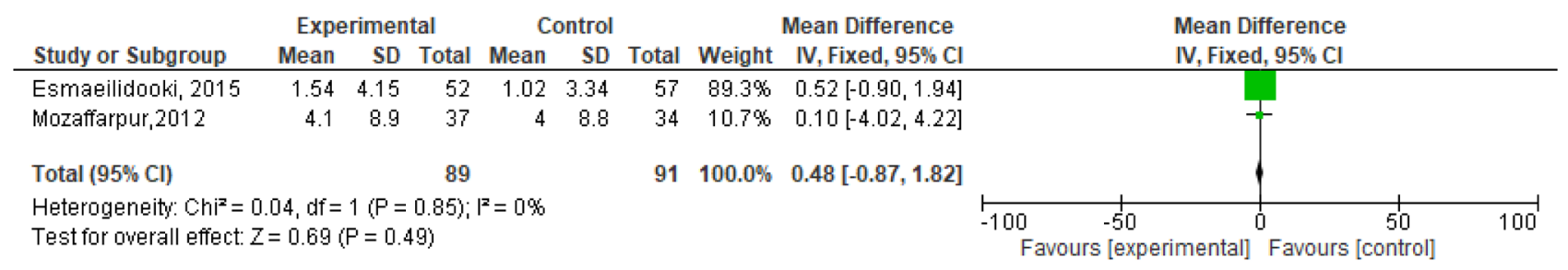

Figure 7. Forest plot in retentive posturing before and after treatment.
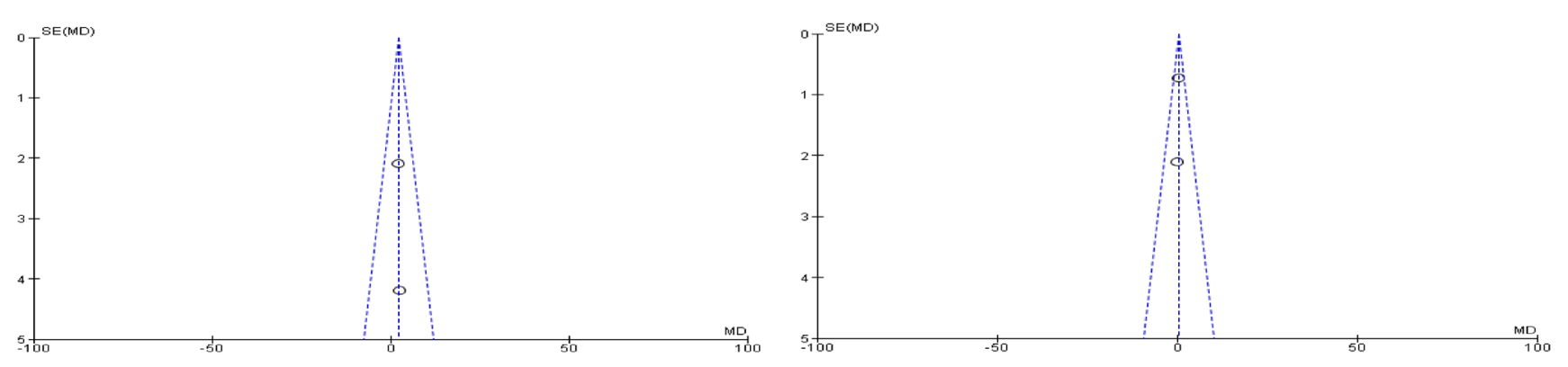

Figure 8. Funnel plot showing overall standardized mean difference in retentive posturing before and after treatment. 


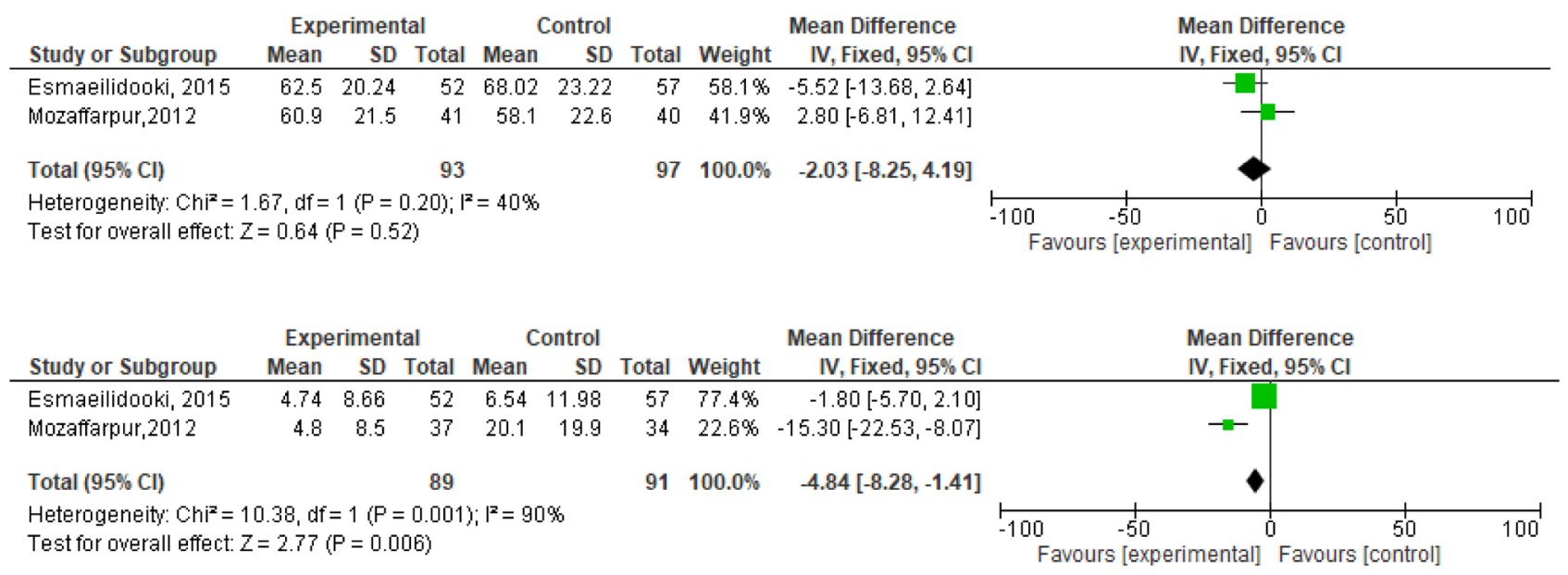

Figure 9. Forest plot in severity of pain before and after treatment.
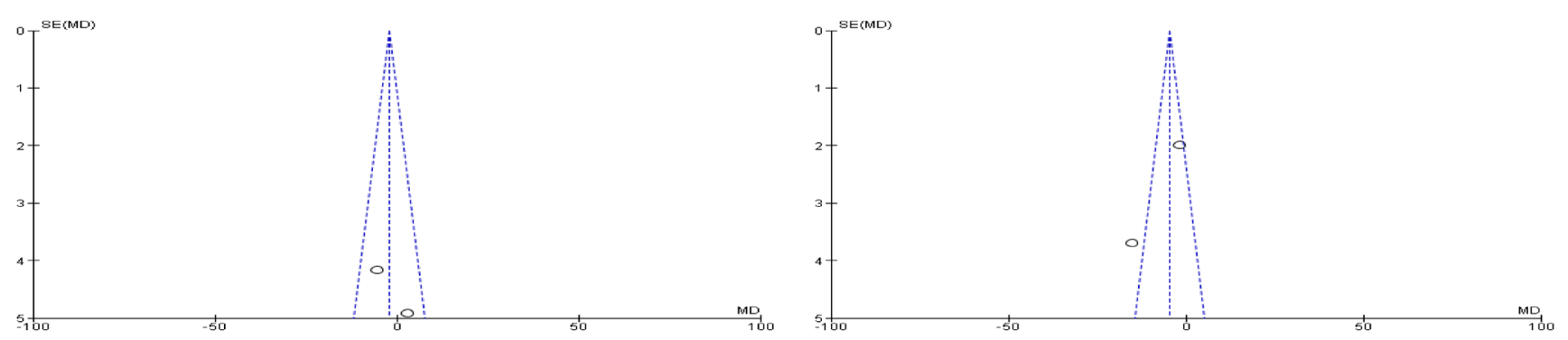

Figure 10. Funnel plot showing overall standardized mean difference in severity of pain before and after treatment.

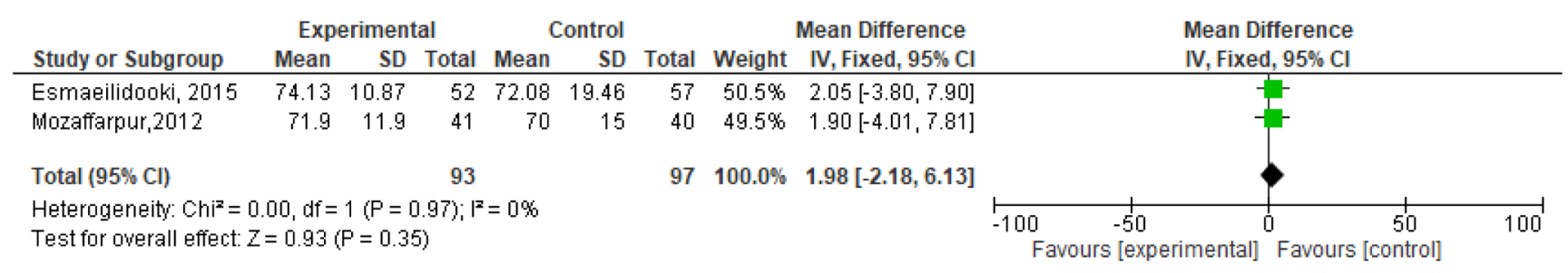

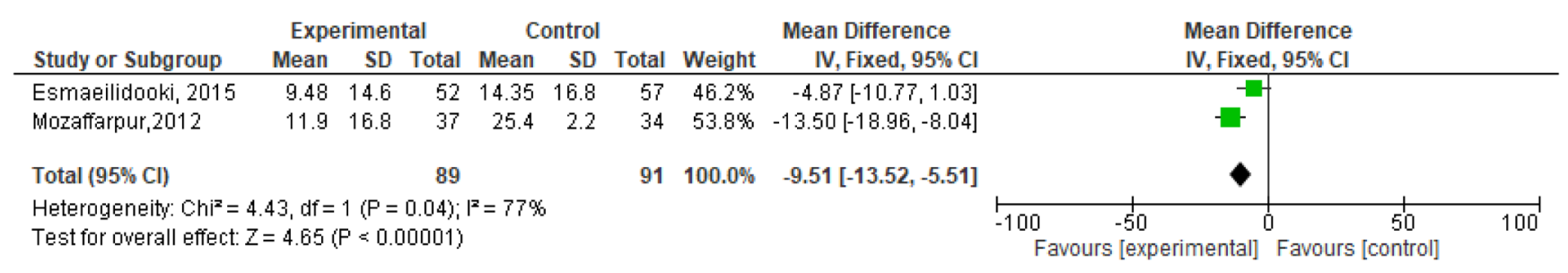

Figure 11. Forest plot in consistency of stool before and after treatment. 

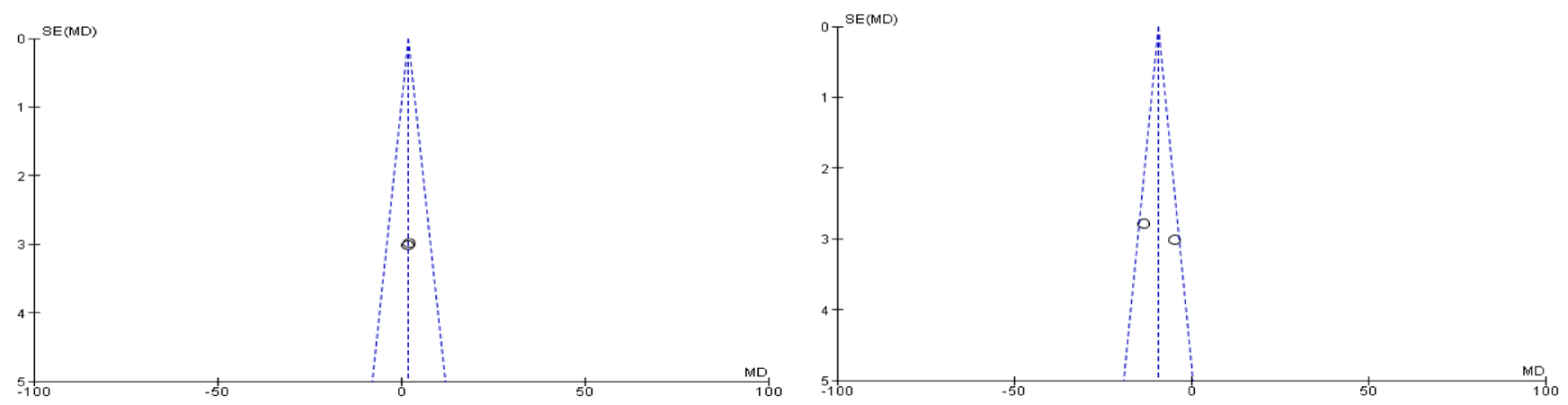

Figure 12. Funnel plot showing overall standardized mean difference in consistency of stool before and after treatment.

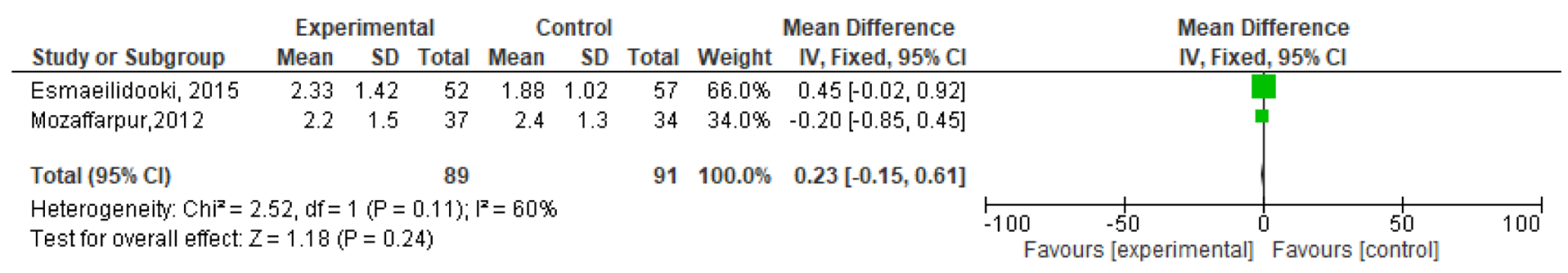

Figure 13. Forest plot in acceptance and tolerance after treatment.

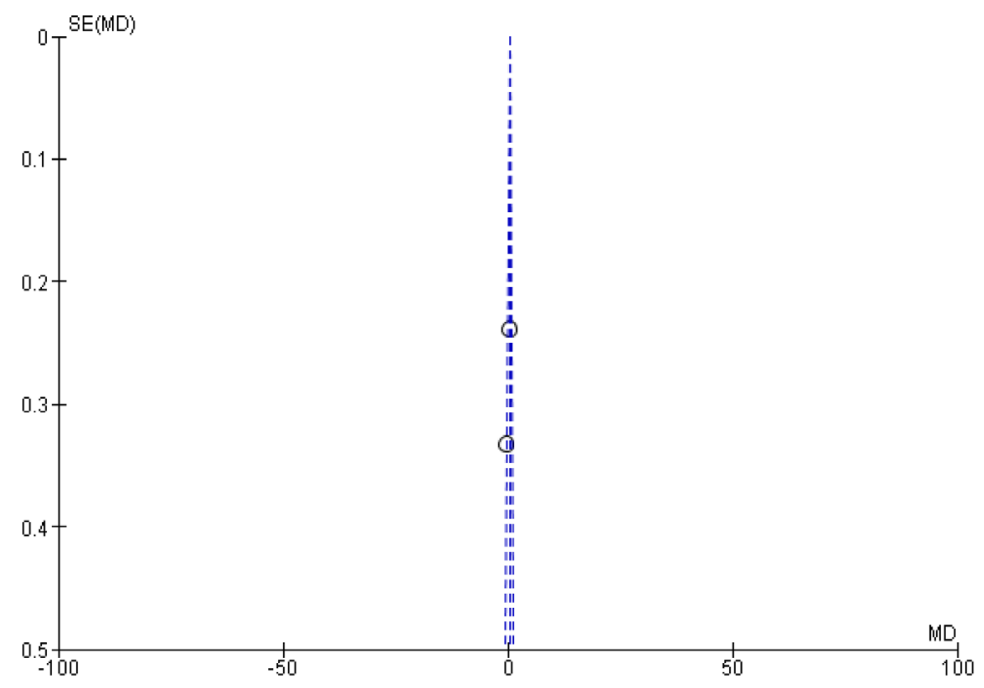

Figure 14. Funnel plot showing overall standardized mean difference in acceptance and tolerance after treatment.

\section{Declarations}

Data availability

Underlying data. Open Science Framework: Application of genus Cassia in thetreatment of Constipation: A systematic review. https://doi.org/10.17605/OSF.IO/PKR4N29

This project contains the following underlying data:

- Cassia Senna for Constipation.rm5 (study RevMan file)
- Quotation Manager.xlsx (study characteristics of citations included in this study)

Reporting guidelines

Open Science Framework: PRISMA diagram and flowchart for the study "Application of genus Cassia in the treatment of constipation: A systematic review". https://doi.org/10.17605/OSF. IO/PKR4N ${ }^{29}$ 
Data are available under the terms of the Creative Commons Zero "No rights reserved" data waiver (CC0 1.0 Public domain dedication).
Grant information

This research was supported by Xiamen University Malaysia.

The funders had no role in study design, data collection and analysis, decision to publish, or preparation of the manuscript.
1. Bharucha AE: Constipation. Best Pract Res Clin Gastroenterol. 2007; 21(4): 709-731.

PubMed Abstract | Publisher Full Text

2. Camilleri M, Ford AC, Mawe GM, et al: Chronic constipation. Nat Rev Dis Primers. 2017; 3: 17095

PubMed Abstract | Publisher Full Text

3. Le Luyer B, Ménard M: [Constipation in children]. Rev Prat. 1998; 48(4): 376-381. PubMed Abstract

4. Liem $\mathrm{O}$, Harman J, Benninga $\mathrm{M}$, et al:: Health utilization and cost impact of childhood constipation in the United States. J Pediatr. 2009; 154(2): 258-262. PubMed Abstract | Publisher Full Text

5. Uc A, Hyman PE, Walker LS: Functional gastrointestinal disorders in African American children in primary care. J Pediatr Gastroenterol Nutr. 2006; 42(3) 270-274.

PubMed Abstract | Publisher Full Text | Free Full Text

6. Nurko S, Garcia-Aranda JA, Worona LB, et al.: Cisapride for the treatment of constipation in children: A double-blind study. J Pediatr. 2000; 136(1): 35-40. PubMed Abstract | Publisher Full Text

7. Gremse DA, Hixon J, Crutchfield A: Comparison of polyethylene glycol $\mathbf{3 3 5 0}$ an lactulose for treatment of chronic constipation in children. Clin Pediatr (Phila). 2002; 41(4): 225-229.

PubMed Abstract | Publisher Full Text

8. Guerra PV Lima LN, Souza TC, et al: Pediatric functional constipation treatment with Bifidobacterium-containing yogurt: a crossover, double-blind, controlled trial. World J Gastroenterol. 2011; 17(34): 3916-3921.

PubMed Abstract | Publisher Full Text | Free Full Text

9. Picon PD, Picon RV, Costa AF, et al:: Randomized clinical trial of a phytotherapic compound containing Pimpinella anisum, Foeniculum vulgare, Sambucus nigra, and Cassia augustifolia for chronic constipation. BMC Complement Altern Med. 2010; 10: 17.

PubMed Abstract | Publisher Full Text | Free Full Text

10. Mozaffarpur SA, Naseri M, Esmaeilidooki MR, et al: The effect of cassia fistula emulsion on pediatric functional constipation in comparison with mineral oil: a randomized, clinical trial. Daru. 2012; 20(1): 83

PubMed Abstract | Publisher Full Text | Free Full Text

11. Thamlikitkul V, Bunyapraphatsara N, Dechatiwongse T, et al: Randomized controlled trial of Cassia alata Linn. for constipation. J Med Assoc Thai. 1990; 73(4): 217-222.

PubMed Abstract

12. Jafri MA, Jalis Subhani M, Javed K, et al:: Hepatoprotective activity of leaves of Cassia occidentalis against paracetamol and ethyl alcohol intoxication in rats. J Ethnopharmacol. 1999; 66(3): 355-361.

PubMed Abstract | Publisher Full Text

13. Abubacker MN, Ramanathan R, Senthil Kumar $\mathrm{T}$ : In vitro antifungal activity of cassia alata linn. Flower extract. Indian Journal of Natural Products and Resources. 2008; 7(1): 6-9. Reference Source

14. Benjamin TV, Lamikanra A: Investigation of Cassia alata, a Plant Used in Nigeria in the Treatment of Skin Diseases. Q J Crude Drug Res. 1981; 19(2-3): 93-96.

Publisher Full Text

15. Singh S, Singh SK, Yadav A: A Review on Cassia species: Pharmacological,
Traditional and Medicinal Aspects in Various Countries. American Journal of Phytomedicine and Clinical Therapeutics. 2013; [cited 2019 Jan 11]; 3: 291-312. Reference Source

16. Patil UK, Saraf S, Dixit VK: Hypolipidemic activity of seeds of Cassia tora Linn J Ethnopharmacol. 2004; 90(2-3): 249-252.

PubMed Abstract | Publisher Full Text

17. Gaddam SA, Kotakadi VS, Sai Gopal DV, et al.: Efficient and robust biofabrication of silver nanoparticles by cassia alata leaf extract and their antimicrobial activity. J Nanostruct Chem. 2014; 4(1): 82 Publisher Full Text

18. Sumathy V, Zakaria Z, Jothy SL, et al.: In vitro and in vivo antifungal activity of Cassia surattensis flower against Aspergillus niger . Microb Pathog. 2014; 77 : $7-12$ PubMed Abstract | Publisher Full Text

19. Yuenyongsawad S, Bunluepuech K, Wattanapiromsakul C, et al:: Anti-cance activity of compounds from Cassia garrettiana heartwood. Songklanakarin J Sci Technol. 2014; 36(2): 189-194, [cited 2019 Jan 11] Reference Source

20. Jung HA, Ali MY, Jung HJ, et al:: Inhibitory activities of major anthraquinones and other constituents from Cassia obtusifolia against $\beta$-secretase and cholinesterases. J Ethnopharmacol. 2016; 191: 152-160. PubMed Abstract | Publisher Full Text

21. Sivakumar V, Ilanhtiraiyan S, llayaraja K, et al:: Influence of ultrasound on Avaram bark (Cassia auriculata) tannin extraction and tanning. Chem Eng Res Des. 2014; 92(10): 1827-1833. Publisher Full Text

22. Ngoc TM, Nhiem NX, Khoi NM, et al.: A new coumarin and cytotoxic activities of constituents from Cinnamomum cassia. Nat Prod Commun. 2014; 9(4): 487-488. PubMed Abstract

23. Jeyaratnam N, Nour AH, Kanthasamy R, et al:: Essential oil from Cinnamomum cassia bark through hydrodistillation and advanced microwave assisted hydrodistillation. Ind Crops Prod. 2016; 92: 57-66. Publisher Full Text

24. Zeng J, Xue Y, Lai Y, et al.: A new phenolic glycoside from the barks of Cinnamomum cassia. Molecules. 2014; 19(11): 17727-17734. PubMed Abstract | Publisher Full Text | Free Full Text

25. Luximon-Ramma A, Bahorun T, Soobrattee MA, et al:: Antioxidant activities of phenolic, proanthocyanidin, and flavonoid components in extracts of Cassia fistula. J Agric Food Chem. 2002; 50(18): 5042-5047. PubMed Abstract | Publisher Full Text

26. Fabricant DS, Farnsworth NR: The value of plants used in traditional medicine for drug discovery. Environ Health Perspect. 2001; 109 Suppl 1: 69-75. PubMed Abstract | Publisher Full Text | Free Full Text

27. Collaboration $\mathrm{C}$ : Cochrane handbook for systematic reviews of interventions. 2008. Reference Source

28. Collaboration C: Review manager (RevMan)[computer program]. 2011.

29. Aslam MS: Application of genus Cassia in the treatment of Constipation: A systematic review. 2019. https://www.doi.org/10.17605/OSF.IO/PKR4N 


\section{Open Peer Review}

\section{Current Peer Review Status: ? ?}

\section{Version 1}

Reviewer Report 28 June 2019

https://doi.org/10.5256/f1000research.19569.r50310

(c) 2019 Shokraneh F. This is an open access peer review report distributed under the terms of the Creative Commons Attribution License, which permits unrestricted use, distribution, and reproduction in any medium, provided the original work is properly cited.

\section{? Farhad Shokraneh}

University of Nottingham, Nottingham, UK

The author investigates the effect of Cassia fistula on three outcomes based on two included studies. It seems a valuable research that could potentially direct the pharmaceutical companies toward a new agent to treat the constipation.

\section{Title}

The title should be "Cassia fistula for treatment of children and adolescents with constipation: A systematic review of randomized controlled trials".

\section{Authorship}

The systematic review requires a process that involves at least two people for screening and data extraction. I suggest the author to find another systematic reviewer to be involved in this work.

\section{Abstract}

The abstract is very brief and sentences are incomplete. Abstract should be re-written following the example from similar systematic reviews and following PRISMA for Abstract.

\section{Minor edits}

1. "act an effective as a laxative" should be "act as effective as laxatives".

2. "search data" should be "search date".

\section{Methods}

1. The standard search filter for finding RCTs as reported in Cochrane Handbook should be used.

2. It is advised in Cochrane Handbook searching Embase, MEDLINE/PubMed, and CENTRAL for systematic reviews of RCTs and this review reports searching only MEDLINE/PubMed.

3. Excluding closed access papers without trying to order them from library or contacting the 
authors introduces full-text or open access bias.

4. The structure of the method should change and start with 1: Eligibility Criteria 2: Databases and search strategy 3: Screening process 4: Data extraction process 5: Assessment of risk of bias process 6: Data analysis plan. Currently, the first section of the methods reports info on search and eligibility criteria while there are specific subheadings for these sections.

5. The rationale behind excluding studies older than 10 years from search date is not clear.

6. The reported number of search results 2207 is not reasonable. A proper search should not find more than 100-200 results for this topic.

7. The search date has not been reported.

8. Following a published Cochrane review of RCTs in terms of structure and all the items in PRISMA Checklist for full systematic reviews is recommended.

9. Constipation is missing from search strategy and MeSH terms in the table.

10. The numbers in PRISMA flow diagram does not match the numbers reported in the text and it does not seem to be correct. Following one of the existing published systematic reviews of RCTs from Systematic Reviews journal or Cochrane Database of Systematic Reviews is recommended.

11. The quality of included studies is being assessed using Cochrane Risk of Bias tool. The role of MQ and using Atlas.ti is not clear in this review. These two are not usually used for SR of RCTs.

12. Studying the meta-analysis section in the Cochrane Handbook which is freely available online could help revising the statistical analysis.

13. Table 2 should report PICOS not SPIO.

14. The time point for the outcome is not clear.

15. The outcome measure has not been described properly.

16. The complications and adverse effects have not been reported in the review.

\section{Results}

1. The sample size reported in the Data Extraction table does not match the numbers in metaanalysis. For example the total for experimental and control group in Review Manager file is 109 for Esmaeilidooki 2016 and 71 for Mozaffarpur 2012 while in the table is 51 and 81 respectively.

2. The analysis for before treatment is not required. All before treatments can be deleted.

3. Funnel plots only work with about $10-20$ studies. All funnel plots can be deleted. 
4. Risk of bias based on Cochrane tool is not clear. It should be low risk, unclear risk and high risk. The current description of Yes/No does not provide enough information.

5. In meta-analysis, "one randomized always analysed" while the numbers in Table 4 are not the numbers in meta-analysis in Review Manager.

6. The control groups in two studies are different so I am not sure if combining the data from two studies in a meta-analysis is a right when there is such heterogeneity in PICOS components.

7. SD is greater than mean is some outcomes which is an indicator of skewed data or error in reporting. Contacting the trials authors might make some of the points clear.

Discussion and Conclusion

Current data and status of the review may not be appropriate for discussion or making a conclusion. The current evidence is limited and more rigorous studies will be required to make any conclusion or recommendations.

I understand the author's passion for conducting a systematic review and so I request the author to work with an expert supervisor in the field before revising the work.

Are the rationale for, and objectives of, the Systematic Review clearly stated? Partly

Are sufficient details of the methods and analysis provided to allow replication by others? Partly

Is the statistical analysis and its interpretation appropriate?

No

Are the conclusions drawn adequately supported by the results presented in the review? No

Competing Interests: No competing interests were disclosed.

Reviewer Expertise: Evidence synthesis, Systematic review, Overview, Scoping review, Rapid review, Randomized controlled trials, Open data, Open access, Open source, Medical journalism, Peer-review, Open source, Outcomes, Interventions, Cochrane

I confirm that I have read this submission and believe that I have an appropriate level of expertise to confirm that it is of an acceptable scientific standard, however I have significant reservations, as outlined above.

Author Response 02 Mar 2021

Muhammad Shahzad Aslam

WHO defines 'Adolescents' as individuals in the 10-19 years. So title cannot changed 


\section{Competing Interests: No}

Reviewer Report 23 May 2019

\section{https://doi.org/10.5256/f1000research.19569.r47237}

(C) 2019 Bellini M. This is an open access peer review report distributed under the terms of the Creative Commons Attribution License, which permits unrestricted use, distribution, and reproduction in any medium, provided the original work is properly cited.

\section{Massimo Bellini}

Gastrointestinal Unit, Department of Translational Research and New Technologies in Medicine and Surgery, University of Pisa, Pisa, Italy

I'm really puzzled about the usefulness of a review which takes into consideration only two papers and altogether only 132 patients. Constipation, as the author himself states, is a very frequent condition, so the conclusions are inevitably flawed by this bias. The author should address this issue in the conclusions

\section{Hence, I have significant reservations.}

Moreover, here enclosed you'll find a copy of the paper. The authors can find some suggestions, as tracked changes and comments to the original manuscript, which could improve the quality of the manuscript.

Are the rationale for, and objectives of, the Systematic Review clearly stated?

Yes

Are sufficient details of the methods and analysis provided to allow replication by others? Yes

Is the statistical analysis and its interpretation appropriate?

Yes

Are the conclusions drawn adequately supported by the results presented in the review? Yes

Competing Interests: No competing interests were disclosed.

Reviewer Expertise: Gastroenterology: Functional Digestive Disorders.

I confirm that I have read this submission and believe that I have an appropriate level of expertise to confirm that it is of an acceptable scientific standard, however I have 


\section{significant reservations, as outlined above.}

\section{Reviewer Response 23 May 2019}

\section{Muhammad Shahzad Aslam}

Dear,

I have read the report. The selected studies were according to the criteria given inside the paper. So, there were only two selected studies for the systematic review. The comments you have mentioned are appreciable. Thanks

\section{Competing Interests: No}

\section{Author Response 02 Mar 2021}

\section{Muhammad Shahzad Aslam}

Please see inclusion criteria (Only articles involving children aged between 2-15 were included. Only articles involving children aged between 2-15 were included.)

Competing Interests: No

The benefits of publishing with F1000Research:

- Your article is published within days, with no editorial bias

- You can publish traditional articles, null/negative results, case reports, data notes and more

- The peer review process is transparent and collaborative

- Your article is indexed in PubMed after passing peer review

- Dedicated customer support at every stage

For pre-submission enquiries, contact research@f1000.com 